Author accepted version

In press, International Journal of Child-Computer Interaction, 10 th December 2015

\title{
Learning to work together: designing a multi-user virtual reality game for social collaboration and perspective-taking for children with autism
}

\section{Sarah Parsons*1}

*1 $_{1}$ For correspondence:

Southampton Education School, University of Southampton, Highfield, Southampton, S017 1BJ, UK

Email: s.j.parsons@soton.ac.uk; Tel : 02380592977

\begin{abstract}
Children with Autism Spectrum Disorders (ASD) find it difficult to engage in reciprocal, shared behaviours and technology could be particularly helpful in supporting children's motivations and skills in this area. Designing educational technologies for children with ASD requires the integration of a complex range of factors including pedagogical and cognitive theories; the affordances of the technology; and the real-world contexts of use. This paper illustrates how these factors informed the design of a novel collaborative virtual reality environment (CVE) for supporting communicative perspective-taking skills for high-functioning children with ASD. Findings from a small-scale study involving eight typically developing (TD) children (aged 8 years) and six children with ASD (verbal mental age 9 years) are also reported. Children with ASD were supported to be reciprocal and collaborative in their responses, suggesting that this CVE could form the basis for a useful technology-based educational intervention.
\end{abstract}

Keywords: virtual reality; collaboration; autism; communication; participatory design; intervention 


\section{Introduction}

Autism Spectrum Disorder (ASD) is characterised by pervasive difficulties in social interaction and communication, and a restricted range of interests and behaviours (APA, 2013). Approximately 1 in every 100 children in the UK (Baird et al., 2006) is diagnosed with an ASD; with around 700,000 people with autism living in the UK (Brugha et al., 2011). The economic cost to society of supporting individuals with autism and their families is significant with the estimated annual cost at $£ 3.1$ billion in the UK, and $\$ 61$ billion in the US (Buescher, Cidav, Knapp, \& Mandell, 2014). Consequently, finding ways to more effectively educate and support individuals with autism to improve outcomes, and decrease reliance on specialist provision, remains a research priority for individuals and their families (Pellicano, Dinsmore \& Charman, 2014). Recent reviews of the research evidence for technologies for autism have underscored both the interest in, and continued potential of, developing and applying technologies for addressing this need (e.g. Boser, Goodwin \& Wayland, 2013; Keintz, Goodwin, Hayes, \& Abowd, 2014; Knight, McKissick, \& Saunders, 2013; Parsons \& Cobb, 2011; Reed, Hyman, \& Hirst, 201; Wass \& Porayska-Pomsta, 2014). Given the significant costs involved in providing specialist provision for autism, it has also been emphasized that technologies may offer a cost-effective and accessible means of assessing, and targeting, children's learning needs (Goodwin, 2008; Grynszpan, Weiss, Perez-Diaz, \& Gal, 2014; Knight et al., 2013).

This paper applies a conceptual model of learner-centred design (Parsons \& Cobb, 2014) to illustrate a novel collaborative virtual environment (CVE) for children with autism, designed with teacher input to support collaboration and reciprocity in behaviour and communication. A preliminary observational study is then reported that explores whether the CVE supported these behaviours between pairs of age-matched children with ASD, and pairs of typically developing children. The study suggests that children with ASD were supported by the structuring of the CVE-based tasks, and teacher facilitation, to collaborate and communicate in a reciprocal way, although they less collaborative and task-focused overall compared to the typically developing children. The following sections describe the background and rationale for 
the design and development of the CVE before presenting the methods and detailed results of the small-scale study.

\section{Background}

\subsection{Designing technologies for children with autism}

The number of peer-reviewed papers on technology and autism has risen substantially since 2001 (Ploog, Scharf, Nelson, \& Brooks, 2013) and evidence from a recent meta-analysis examining learning outcomes for children with autism in technology-based interventions showed positive results (Grynszpan et al., 2014). These reviews call for further research to explore the benefits of technology-based educational intervention more widely and to strengthen the evidence base. Notably, Ploog et al (2013) concluded that: "Properly designed CAT [computer-assisted technologies] programs may be advantageous in helping children with ASD attain skills for increased adaptive functioning. A problem that often arises is that the majority of the available programs have not been developed specifically for this population" (p.319; emphasis added). This leads to the question: what does it mean for a technology to be specifically designed for children on the autism spectrum? Researchers have provided some insights although the following suggestions are by no means exhaustive or definitive.

Firstly, there seems to be agreement that educational technologies for autism should be designed for supporting learning in the core areas of difficulty characteristic of an ASD diagnosis i.e. social communication and interactions. For example, technology-based research has targeted (inter alia) social conversation, language, play, and adaptive behaviours (Ploog et al., 2013; Wass \& Porayska-Pomsta, 2014). Understanding, and focusing on, the core difficulties of autism as the basis for designing effective educational curricula is not confined to technology-based learning approaches, and is recognised as best practice in autism education generally (Guldberg, 2010; Guldberg et al., 2011; Jordan, 2005; Prizant \& Rubin, 1999; Ravet, 2011).

Secondly, the value and importance of user-centred design has been recognised, with researchers often incorporating the views of parents, practitioners and children with autism 
into the development of technology-enhanced learning (TEL) environments for autism (e.g. Cobb et al., 2002; 2010; Madsen et al., 2009; Parsons et al., 2000; 2011; Porayska-Pomsta et al., 2012). The emphasis on user-involvement is not specific to autism but reflects a wider understanding about the ethical and practical advantages of gaining insights from the intended user population in technology design (e.g. Abascal \& Nicolle, 2005; Brown et al., 2011; Nesset \& Large, 2004). Nevertheless, there are valuable discussions about the extent to which the methods that are used to involve users and seek their views need to be adapted to accommodate autism-specific characteristics and communication strengths / preferences. For example, when involving children with autism, researchers have successfully used more visual and structured methods and materials, and provided concrete examples to initiate and prompt ideas rather than relying on abstract concepts for discussion (Benton, Johnson, Ashwin, Brosnan, \& Grawemeyer, 2012; Davis, Dautenhahn, Powell, \& Nehaniv, 2010; Millen, Cobb, \& Patel, 2011).

Thirdly, there is increasing awareness about the need to consider the situated context of use in which the learning is intended to take place; in other words, to move away from a "technologically determinist perspective" (Abbott, 2007; p.7) towards the development and implementation of technologies in the places where people are actually going to want to use them i.e. in homes and schools (e.g. Frauenberger, Good, Alcorn, \& Pain, 2013; Harrison, Sengers, \& Tatar, 2011; Kasari \& Smith, 2013; Ogletree, Oren, \& Fischer, 2007). It is important to involve members from the autism community in order to evolve a more ethical, informed and situated approach to research (Pellicano et al., 2014; Pellicano \& Stears, 2011), and so interdisciplinary teams are essential (Beardon, Parsons, \& Neale, 2001; Porayska-Pomsta et al., 2012). Consequently, there is a need for researchers to work much more closely with schools to develop meaningful and context-appropriate ways of supporting the learning of children with ASD (Parsons et al., 2013). Therefore, while there are non-autism-specific as well as nontechnology-specific principles that can be applied to designing technologies for autism, it is also crucial to be informed by a good understanding of autism in order to decide whether there are 
specific features that need to be considered to more effectively support children's learning (cf. Jordan, 2005).

2.2. Theory, Technology and Thoughts (3T): conceptual approach to the learner-centred design of technologies for autism

Parsons and Cobb (2014) argue that designing educational technologies for autism is complex territory, requiring consideration and integration of a range of factors. They propose a "tripledecker sandwich" (p.421) model of learner-centred design for autism focusing on Theory, Technologies and Thoughts (3T), as a way of making explicit the many design decisions and influences that impact on how educational technologies are developed. The authors argue that the sandwich metaphor makes sense because only by bringing all three layers together can an effective product (sandwich) be made to support successful learning outcomes for children. The 3T model is applied below to illustrate the design decisions involved in the creation of a CVE called Block Challenge. This was one of the prototypes produced in the COSPATIAL project which was funded by the European Commission FP7 Programme to develop collaborative technologies to support the engagement and communication of children with autism in the classroom (Cobb, Parsons, Millen, Eastgate, \& Glover, 2010; Weiss et al., 2012). Inspiration for the 3T model came from early scoping of the field and the identification of "best practice" features of technology design for supporting the learning of children with autism (Parsons, Garib-Penna, et al., 2011) ; the 3T model was further refined and clarified through the development of the Block Challenge prototype (Parsons \& Cobb, 2014).

The core aspects of the 3T model described by Parsons and Cobb (2014) for designing educational technologies for autism are:

1. Theory -the top-down disciplinary theories that are used to inform the development of educational tasks;

2. Technologies - the specific affordances of the technology/ies developed and applied for supporting learning and interaction; and 
3. Thoughts - the grounded, bottom-up influences of the intended context(s) of use and the perspectives of the target users (e.g. children, parents, teachers, other professionals).

\subsection{Illustrating the 3T model approach in practice}

In terms of Theory the development of Block Challenge drew upon constructivist theories of learning which emphasize the importance of learners working together on tasks and being scaffolded in their learning via peers and teachers. There is good evidence from technologybased (e.g. Higgins, Xiao, \& Katsipataki, 2012) and non-technology-based research (Aronson \& Patnoe, 2011; Davis et al., 2004; Nind \& Wearmouth, 2006) about the value of such pedagogical approaches for promoting good learning outcomes for children, including those with special educational needs (SEN). There is also good evidence that peer interactions can promote positive social outcomes for children with autism when paired with typically developing children (Owen-DeSchryver, Carr, Cale, \& Blakeley-Smith, 2008; Whitaker, 2004) and other children with autism (Loncola \& Craig-Unkefer, 2005).

Additionally, theories concerning the needs of autistic learners were helpful regarding the best practice requirement for focusing on core difficulties as targets for educational intervention (noted above); in this case, the socio-cognitive difficulties experienced by children on the autism spectrum relating specifically to collaboration and reciprocity in behaviour and communication (McConnell, 2002; Williams White, Koenig \& Scahill, 2007). In this context, Bauminger (2002; 2007a \& b) demonstrated that supporting children with autism to focus on both thinking and behaviour, and to reflect on their experiences and observations with peer or teacher facilitation (i.e. scaffolding), can effectively support social understanding. Thus, we drew across these theories to specify that the prototype design needed to (a) target core difficulties in reciprocal social communication and interaction; (b) support children's thinking and behaviour; (c) scaffold children's interactions; and (d) enable children to work on tasks with each other in an engaging way. 
The affordances of the Technology, therefore, needed to be in alignment with this theoreticallyinformed approach. Given the focus on collaboration in the project, we selected technologies that could only be used by more than one person interacting with them concurrently: CVEs and Shared Active Surfaces (SAS). The prototype discussed here was a CVE and so the SAS will not be discussed further (but see Bauminger, Eden, Zancanaro, Weiss, \& Gal, 2013, and Zancanaro et al., 2014, for more details). The bespoke CVE was a 3-D virtual space, which could be navigated in real time, and allowed more than one user to interact with the scene and each other. The focus on collaborative technology adds to the small, but growing literature that explores the potential benefits of encouraging children with autism to interact with peers and / or teachers via technologies that promote engagement and interaction in different ways (Cheng \& Ye, 2010; Dillon \& Underwood, 2012; Holt \& Yuill, 2014; Menzies, 2011; Schmidt, Laffey, Schmidt, Wang, \& Stichter, 2012). Such approaches move beyond the limitations of a one-user / one-computer setup and didactic learning approaches common in earlier studies (e.g. Bosseler \& Massaro, 2003; Silver \& Oakes, 2001) and have shown promise in supporting children to work together on tasks. The 3-D affordances of virtual environments have been argued to support "more effective collaborative learning" (Dalgarno \& Lee, 2010; p.10) than 2-D programmes. Indeed, Dickey (2005; p. 122) suggests that there is "compelling evidence of the potential that graphically rich three-dimensional settings provide for constructivist learning activities". Parsons and Mitchell (2002) also argue that, for children with autism specifically, VEs can be designed to incorporate both behavioural and cognitive approaches to learning, thereby aligning with the project's theoretically-informed aim to support both aspects. Additionally, CVEs support different users to share the same virtual space but from individual computers, which means that each user has a unique perspective on any shared virtual scene or interaction (Dickey, 2005). In other words, in order to connect and communicate with others in the same virtual space, users need to take into account that others will see and experience the scene differently from themselves. Given the fundamental importance of communicative perspective-taking for interpreting language appropriately and interacting socially (Nilsen \& Fecica, 2011; Williams White et al., 2007) this is 
an affordance of a CVE that enables interactions to be designed to target and strengthen skills in this area for children with ASD. Finally, given the conceptual importance of scaffolding for supporting learning, CVEs allow for prompts to be designed into the structure of the game itself as well as for facilitation to be provided by peers and teachers physically sat alongside children and / or interacting with them in the CVE (Yelland \& Masters, 2007).

Indeed, teacher's views about how and when such facilitation could be provided for children formed a strong part of understanding the Thoughts and territory of the intended users.

Teachers from both special and mainstream schools, as well as children, with and without ASD, were involved throughout the project in a range of learner-centred design activities (Parsons \& Cobb, 2014). These activities informed the look and feel of the Block Challenge game, the pedagogical structure of the tasks, as well as how interactions could be supported and rewarded within and around the CVE; for example, teachers and children suggested the use of a reward tool bar where users could collect stars for collaborative interactions (see Millen, 2014 for more details). Importantly, the project worked in schools from the start and so ensuring that the CVE could run on standard desktop or laptop computers that are frequently used in schools was essential.

\section{Implementing the learner-centred design of the Block Challenge CVE}

\subsection{Description of Block Challenge}

The Block Challenge CVE was built in DEMON [3-Dimensional Environment for Multiuser

simulations $\left.{ }^{1}\right]$, run on standard laptop computers using a mouse for interaction. Block Challenge was designed as a two-player CVE game in which children had to verbally communicate and collaborate with, and understand the perspective of, the other child in order to be successful in completing the game. Each player takes a different first-person perspective within the CVE such that they can see and interact with other people in the environment but they always maintain their own perspective within the scene. A screen was used to separate the children to ensure

\footnotetext{
${ }^{1}$ Both DEMON and the Block Challenge CVE were built by COSPATIAL partners at the University of Nottingham, UK.
} 
that they focused on the CVE and communicated with their partner via the game (using microphone headsets) rather than face-to-face. A facilitator (teacher or researcher) sat next to each child and had access to guidelines and checklists, which were printed in a manual before and during the session (see Fig 1).

${ }^{* * *}$ Insert Fig 1 about here ${ }^{* * *}$

\subsection{Training Phase}

With the help of a facilitator, children were introduced to "Professor Blocks", a virtual character programmed into the software that provides instructions and feedback on children's performance (see Fig 1). Children are prompted to navigate through the CVE, to ensure that they understand simple visual perspective-taking (c.f. Hamilton, Brindley \& Frith, 2009). They also watch a short instructional video about how to play the main game.

\subsection{Main Task}

Pairs of children have to choose and stack virtual dual-coloured blocks together and communicate with each other to establish that the chosen block enables them to match their own target (only seen by themselves) as well as their communication partner's. Each child's colour targets were composed of two block towers and were different to their partner's but children always had the choice to collaboratively select a block with both their colour targets from an array (e.g. Child A needed a red block and Child B needed a yellow block, and the correct block for them to select from an array was the one that was half red and half yellow). After children had selected a block, it appeared in the middle of the room in the incorrect orientation relative to the two children; with the two sides of the block showing the two colours facing both children, rather than with the side with only their target colour facing them. Children then needed to collaboratively rotate the block into its correct orientation. Once rotated into the correct orientation children had to agree whether to 'keep' or 'swap' the block, after which they would receive feedback from Professor Blocks with further instructions if their block or rotation choices were incorrect, and a prompt to communicate with each other to resolve the problem. 
There were three levels of difficulty in this CVE prototype: (1) only the two blocks (one for each level of the tower) needed to complete the task with no distracter blocks; (2) the two blocks needed to be successful on the task plus two distracter blocks not sharing any of the target colours; and (3) the two target blocks plus alongside four distracter blocks, each containing one of the target colours, thereby making it more difficult to find and select the blocks that match the needs of both players.

\subsection{Pairing and facilitation}

Children took part within TD-TD or ASD-ASD pairs. This approach was considered important as part of this study for understanding (a) how TD pairs of children approached the task generally; (b) whether TD pairs differed in important ways in their responses to the task compared to children with ASD; and (c) whether pairs of children with ASD could be supported to effectively interact with each other through the CVE medium. The latter was particularly relevant in the context of educational provision for children with ASD, which often involves ASD-specific group work on social understanding, even in the context of mainstream (general) educational provision (e.g. Wittemeyer et al., 2011). In addition, given the importance of scaffolding of understanding taking place within a reasonable zone of proximal development between pairs of children, we did not want to pair ASD-TD pairs initially in case the gap between them in their reciprocal communication was too large and, therefore, the task too demotivating.

Facilitators were provided with a short instruction booklet explaining the purpose of the game and how to support children during their use of it (Cobb et al., 2010). In addition, facilitators received further personal guidance from the research team, explaining their role was to help children with anything that needs clarifying or by giving any prompts above and beyond the program instructions when and where necessary. In cases where children made errors, showed poor perspective taking or displayed non-collaborative behaviours, the role of the facilitator was to prompt children to correct those errors and to help them understand a preferred course of action or why a misunderstanding occurred. Facilitators were encouraged to let children 
complete the task as independently as possible and to provide support and encouragement, or modelling of appropriate responses, if required. The interactions between pairs of children were intended to be child-led, rather than adult directed; with adults providing a contingent, responsive and supportive role as needed.

\section{Small-scale evaluation of the Block Challenge CVE}

\subsection{Participants}

Participants were recruited from three mainstream primary schools and one mainstream secondary school in England that had expressed an interest in the project and a willingness to take part. All of the typically children attended one of the primary schools; one pair of children with ASD came from each of the three other schools. The head teacher gave permission for the research to be conducted and for parents and teachers to be asked for their consent for participation. Parents provided informed consent for their children to take part and children were provided with age-appropriate information for assenting to their own participation. The teachers also provided their informed consent to take part. The project was reviewed and approved by the University of Birmingham's Social Sciences ethics committee.

14 children and five facilitators (two teachers and three researchers) took part: six children had an ASD and were aged 10-13 years; eight were typically developing (TD) and aged 7-9 years. All children with ASD were selected for inclusion in the study on the basis of diagnostic information within their Statements of Special Educational Need. Children's parents were asked to complete the Social Communication Questionnaire (SCQ; Rutter, Bailey \& Lord, 2003) to confirm autism characteristics. Two were not returned but the scores for the remaining four children in the ASD group were 31, 25, 20 and 15 (with scores of clinical significance being 15 or above).

\subsection{Procedure}

All sessions took place on school premises, in a quiet room away from the child's main classroom and were videotaped for subsequent analysis. Children took part in three sessions in fixed order, each lasting approximately 30 minutes on separate days, over the course of two 
weeks. In the first session, all children were assessed for language (BPVS-III; Dunn, Dunn, Styles, \& NFER - Sewell, 2009) and IQ (WASI; Wechsler, 1999). Children in the TD group were matched group-wise to children in the ASD group on verbal mental age (VMA), as assessed by the BPVS. Children with ASD were older than the TD children but otherwise similar in terms of these background characteristics (see Table 1).

In the second session, children's ability to take the perspectives of others was assessed via a standard first-order change of location (Baron-Cohen, Leslie \& Frith, 1985) and second-order (“John thinks that Mary thinks..."; Perner \& Wimmer, 1985) Theory of Mind (ToM) task. Table 1 shows that all children apart from one child with ASD passed the first-order task, and only 4 children (2 ASD, 2 TD) passed the second-order ToM task. Children's executive function abilities were also assessed via the BADS-C (Emslie, Wilson, Burden, Nimmo-Smith, \& Wilson, 2003), which comprises specific sorting and problem-solving tasks, as well as the DEX-C questionnaire, which asked teachers to rate children's everyday executive behaviours on a 5-point scale from "Never" to "Very Often" (e.g. "Finds it difficult to stop doing something even if he or she knows they shouldn't"). Table 1 also shows that while the children with ASD had more executive difficulties than the TD pairs overall (as would be expected), the children were very similar on the ToM measures, language and IQ. Table 2 shows the breakdown of performance on these background tasks for each child within each pair, along with the total number of moves made by each child and facilitator.

In the third session, children were paired together based on friendship judgements made by the teachers and were supported in using the Block Challenge CVE, moving through the training phase and then into the main game. All pairs of children knew each other, and were in the same classes at school.

*** Insert Tables $1 \& 2$ about here*** 


\subsection{Analysis}

This descriptive small-scale study aimed to establish whether Block Challenge enabled the reciprocal, communicative perspective-taking interactions between children, as well as scaffolding behaviours between teachers and children, that it had been designed to do. A detailed coding system was developed for the child-child interactions using the software Transana (Woods \& Fassnacht, 2010), based on the approach taken by Mavrou (2007; Mavrou, Lewis \& Douglas, 2007; 2010) who analysed the communication of pairs of children working together on computer-based tasks. Mavrou's (2007) codes were inductively modified to reflect the specific features of the Block Challenge task, undertaking a line-by-line thematic analysis of the children's verbal and non-verbal "moves", which were then conceptually grouped into collaborative and non-collaborative interactions based on Holt and Yuill's (2014) coding of autistic children's interactions on computer-based collaborative tasks. The analysis focused on three main aspects of the interactions:

(i) Interactional "moves" between the children: the number of moves that each child took within each of the three levels of Block Challenge was counted to provide an indication of how much each child contributed to the interactions. A "move" was defined as a verbal or non-verbal behaviour directed at the other child and represented by the coding of a single line of the transcript (see Figure 2 for an excerpt of the time-flow of interaction which illustrates the lineby-line coding). The total number of moves can be considered a proxy indicator of reciprocity between the pairs in the sense that the game cannot progress unless children mostly contribute in a reciprocal manner, taking turns to complete each stage of the task. This structure was designed into the game to ensure that children were supported in making reciprocal exchanges. It is difficult to represent fully the exact sequences of interactions between the pairs because of the high total numbers of moves involved; nevertheless, Figure 2 provides an insight into how moves were represented between children, and also between children and facilitators. 


\section{***Insert Figure 2 about here ${ }^{* * *}$}

(ii) Peer-peer communication: the full coding system used to analyze the communication within the child pairs is shown in Table 3. These codes include verbal and non-verbal behaviours, which were represented separately within the coding scheme (e.g. see 'Accept', and 'Acting with no description'); the majority of codes represented verbal behaviours, reflecting the specific task demands of Block Challenge. An independent coder who was not part of the core research team provided an inter-rater check on the coding from one full transcript of one pair of children with ASD; with agreement at 84\% (145/172 codes). The fine-grained nature of the coding scheme was intended to discriminate between responses in order to avoid the use of multiple codes for individual behaviours. This high rate of inter-rater agreement in the context of such a detailed coding system suggests that the scheme was successful in this regard, although even stronger reliability and validity could have been demonstrated had inter-rater coding been extended to a wider sample of the data. Unfortunately, time and resource considerations precluded this.

Given that the objective of Block Challenge was to support communicative perspective-taking and reciprocity via collaboration, the fine-grained codes were grouped conceptually into behaviours that indicated collaboration and task engagement and those that did not. This grouping was based on Holt and Yuill's (2014) coding of autistic children's behaviours in a collaborative computer-based task. Their approach was adopted because Holt and Yuill's (2014) analysis specifically sought to capture the interdependent nature of the interactions between children with ASD in the completion of a collaborative computer-based task, and separate these from behaviours that did not support task completion or were not reliant on co-operation from the other child. The present study, in line with Holt and Yuill (2014), aimed to reflect that some behaviours were intentionally targeted at the other child in the paired task, while other behaviours were related to the technology or to the task, or to the facilitator, but not directly to the peer. In other words, it was important to show that children could still be co-operative and task-focused without direct communication with each other, including taking into account the 
support received from the facilitator. Thus, there was a strong conceptual alignment between Holt and Yuill (2014) and the present study, not least in seeking to capture the capabilities and active engagement of the children, rather than focusing on absences or deficiencies in behaviours. Holt and Yuill's (2014) coding was mostly based on non-verbal behaviours due to the nature of their task and the inclusion of less verbally able participants. The extension of their coding scheme to the present study, focusing on mostly verbal behaviours with more able participants, also represents a valuable contribution to knowledge.

The conceptual categorization of the fine-grained coding was discussed and checked with Holt and Yuill directly (personal communication). Specifically, the fine-grained codes were grouped into four main categories (see Table 3):

- Active other-awareness (ACO) - indicates an intentional, contingent relationship to partner's comment or action relating specifically to successful task completion e.g. explicitly co-ordinating actions to complete the task;

- Attentional other-awareness (ATO) - related to but not contingent on the other's action with the aim of further progressing or completing the task e.g. clicking agree but without explicit acknowledgement or further action;

- Approach to task (APT) - task-related but not directed at the other child e.g. navigating the screen or task buttons on own screen;

- Withdrawal from task (WFT) - not task-related e.g. showing frustration, ignoring the other child, disrupting the task, moving around the virtual space without trying to complete the task successfully.

***Insert Table 3 about here ${ }^{* * *}$

(iii) Teacher facilitation: each facilitator move (communication directed towards the child) was counted and coded on a line-by-line basis using the transcript and the video footage, again taking an inductive approach to describe how the facilitators were supporting children's 
engagement with the task and each other (see Table 4). Independent inter-rater coding for one full transcript showed agreement of 95\% (112/118 codes). The utterances made by children and facilitators were single statements or questions that could be coded in one category and these are presented as frequencies below.

\footnotetext{
*** Insert Table 4 about here ${ }^{* * *}$
}

\section{Results}

The results are presented according to the three main categories for analysis introduced in Section 4.3. First, the data that shows the reciprocity of communication between the pairs of children by analysing their interactional "moves" during the game; second, the within-pair communication between the children analysed using Holt and Yuill's (2014) collaboration categories; and third, the amount and nature of facilitation provided by teachers according to frequency and purpose of the instructions or comments.

\subsection{Reciprocity of the children}

Figure 3 shows the total number of moves taken by each pair to complete the three levels of the task. The ASD pairs tended to take more moves than the TD children overall ( 451 vs. 352 respectively), although TD pair 4 took more moves than ASD pairs 1 and 2. Closer examination of the interactions in TD pair 4 showed that they tended to use each other's name to establish initial attention [“Jenny?" "Yeah...”] before proceeding with the task [“I need to rotate"] rather than a fundamental difficulty with the task. ASD pair 3 took many more moves to complete the task compared to the other pairs. Comparing the frequency of moves taken within each pair there were no significant differences for either the ASD or TD children, according to chi-squared analyses. This suggests that children within the pairs were contributing equally to the task. There was a general trend in most of the pairs (apart from ASD3 and TD2; see Figure 4) for the number of moves to decrease as the game became more difficult over the levels, suggesting that communication became more efficient as children became more familiar with the task. 


\section{***Insert Figs $3 \& 4$ about here***}

\subsection{Peer-peer communication}

Figure 5 summarises the average total number of behavioural codes for each group based on Holt and Yuill's (2014) four main categories, and Table 5 presents the number of, and average, codes per pair and per group, according to each category. The overall pattern of responses across the four main categories was similar for both groups (Figure 5), suggesting that the pairs of children approached the task in similar ways. In all categories, the ASD pairs had higher frequencies overall than the TD pairs, with the majority of behaviours in the Active otherawareness (ACO) and Approach to Task (APT) categories (Table 5). The ASD pairs also showed more off-task behaviour with higher frequencies in the Withdrawal from Task (WFT) category. There were some slight variations from this overall pattern within some pairs (see Table 5), for example ASD3 were less communicative with each other relative to the other ASD pairs, and TD4 were more communicative with each other, relative to the other TD pairs (see also section 5.1 above). Nevertheless, the overall pattern of higher frequencies in the ASD group remained even when the number of moves was controlled for. The overall ratio of collaborative / on-tasks $(\mathrm{ACO}+\mathrm{ATO}+\mathrm{APT})$ to non-collaborative/ off-task (WFT) behaviours across the pairs in each group was 38:1 in the TD group and 9:1 in the ASD group. This suggests that even though the ASD pairs showed high levels of engagement with each other, and the task, they were less collaborative and task-focused than the TD pairs overall as a proportion of the total number of behaviours observed.

\footnotetext{
${ }^{* * *}$ Insert Fig 5 and Table 5 about here***
}

\subsection{Teacher facilitation}

The number of moves taken by teachers to support children's responses is shown in Figure 2. A relatively high level of facilitation was provided for ASD pairs 1 and 3 compared to the others, while ASD2 received the lowest level of facilitation overall and pair TD4 received more facilitation relative to the other TD pairs. It is interesting to note in this context that both 
children in ASD2 passed the second-order ToM task, while both children in TD4 failed the second-order ToM task (Table 2), though a low level of facilitation was also observed in TD2, both of whom also failed the task. Figure 6 shows the nature of facilitation provided across the pairs in each group based on the interpretive codes shown in Table 3. Mostly, the overall pattern of facilitation for the TD and ASD pairs was similar, although frequencies were generally higher in all categories for the ASD group. It is noticeable that more facilitation was provided overall for the ASD pairs in the Task and Procedure categories, as well as in the Concept and Communication categories, relative to the TD pairs.

\footnotetext{
${ }^{* * *}$ Insert Fig 6 about here ${ }^{* * *}$
}

\section{Discussion and conclusions}

The results of this descriptive, proof-of-concept study showed that pairs of children with ASD and pairs of TD children communicated with each other throughout the Block Challenge task and in mostly similar ways. The children with ASD made sustained endeavours to communicate with their partners during their use of Block Challenge and were as reciprocal in their communication as the TD children. Indeed, the pairs of children with ASD made more communicative moves to their partners than the TD children, even when the total number of moves was taken into account. It could be that the ASD pairs maintained communication because they did not or could not make assumptions about their partner's knowledge in the way that the TD children did. For example, once they quickly became used to the game, the TD children sometimes acted after reading the instructions from the screen without necessarily communicating with their partner, possibly because they found the task too easy and / or made assumptions about what their communication partner did or did not know about the target. Anecdotally, when talking about the task following the session some of the TD children suggested that they found the task too easy and would have liked it to be harder, but this would be something worth investigating specifically in future studies. Moreover, given the small-scale nature of the study and the small 
numbers of children involved it is not possible to confirm the stability of any putative differences between pairs and so results should be interpreted with caution.

By contrast, some of the children with ASD struggled (as expected) with the conceptual and communicative demands of the task, compared to the TD children, despite being matched with them on verbal ability. Reflecting these difficulties, the ASD pairs of children on average received more than double the input from facilitators sat alongside them compared to TD pairs and made more moves to get to the same successful outcome compared to most of the TD children. In addition, even when taking into account the total number of moves made within each pair, the ratio of collaborative, task-focused behaviours to task withdrawal behaviours was much higher for the children with ASD, compared to the TD pairs. This suggests that communication between the ASD pairs was less efficient, or at least less targeted and effective, compared to the TD children, corresponding with similar findings on different communication tasks (Dahlgren \& Dahlgren-Sandberg, 2008; Nilsen \& Fecica, 2011). Nevertheless, there was a trend in most pairs of children in our study for the number of turns to decrease across the three levels of the game despite the increasing difficulty of the task, suggesting that a reduction in the number of turns could signal an improvement in children's targeted communication as they became more familiar with the task.

These findings are encouraging for at least two reasons: firstly, they suggest that Block Challenge seems to be effectively and appropriately targeting the specific communicative and conceptual challenges that we planned from the start and secondly, that - with supportive input from facilitators - children with ASD can, nevertheless, complete the tasks successfully despite their well-documented difficulties in social reciprocity (see Williams-White et al., 2007 for a review). Successfully completing the Block Challenge task requires that children take into account the perspective of their communicative partner because it was designed in such a way that the task could not be completed unless children did this. Thus, the fact that all pairs of children 
completed the three levels of the game, albeit with varying degrees of help from the facilitators, demonstrates that they were able to consider their partner's perspective even though the majority (in both the TD and ASD pairs) failed the standard second-order ToM task. Therefore, Block Challenge seems to provide an educational context in which social communication, perspective-taking and reciprocity can be encouraged and practised between ASD peers and scaffolded effectively by teachers, in support of previous research (Mitchell, Parsons \& Leonard, 2007; Parsons, Leonard \& Mitchell, 2006; Prendeville, Prelock, \& Unwin, 2006). This demonstrates that Block Challenge appears to be pitched at a level that allows children with these ability profiles to be successful (with support) but which also effectively targets core difficulties in social communication, in line with our planned design approach.

There was a tendency for some of the children with ASD to show more non-task related behaviours (categorised as 'Withdrawal from task') than the TD pairs within their use of the CVE. This is consistent with the findings of Parsons, Mitchell and Leonard (2005) who showed that a subset of children with ASD - with lower verbal and executive abilities - tended to be more exploratory and less task-focused in their use of a single-user VE compared to TD children. Although the numbers are small, and so this interpretation is necessarily cautious, some of the children with lower verbal and executive abilities, who also failed the second-order ToM task, showed these behaviours in the present study (pairs ASD1 and ASD3). Perhaps unsurprisingly, these were also the children who received the most support from facilitators. This reinforces the importance of documenting the background profiles of the children who struggled the most on these tasks, as well as the pedagogical roles that the facilitators played in helping children to complete the tasks successfully (Schmidt et al., 2012). This also suggests that a case study approach to investigating children's performance on the task would be valuable in future studies so that background characteristics and context can be clearly represented (c.f. Ke \& Im, 2013). Such an approach could also be applied to exploring the interactions between different pairs of 
children (e.g. mixed ASD + TD) to see whether Block Challenge could be useful for supporting communication in inclusive settings.

As a small-scale study there are limitations that need to be acknowledged. Although most parents completed the SCQ to confirm their child's autism characteristics, two parents did not return this information and so the data were incomplete in this regard. We had confirmation from formal school records regarding the professionally identified needs of the children however, the strongest confirmation can be obtained from the completion of the Autism Diagnostic Observation Schedule (ADOS; Lord et al., 1989). It was also not possible to ascertain background information about the children that may influence their interaction with the CVE, e.g. fine-motor skills, visuo-spatial abilities, and technology use more generally. Finally, while the inter-rater coding provided a good indication of reliability using a detailed coding scheme, it would have been even stronger if a larger proportion of the data had been checked.

Overall, this study suggests that this novel CVE technology is appropriate and motivating for children with ASD and, therefore, establishes a valid proof-of-concept basis for using Block Challenge as a learning intervention between higher-functioning pairs of children, focusing on collaboration and reciprocity of communication. A larger-scale study incorporating the technology has been undertaken and will be reported in due course. The 3T design approach taken, incorporating Theory, Technology and Thoughts, was successful in supporting the design of an ASD-specific technology and offers a helpful framework for informing the design and development of future educational technologies in this area. 


\section{Acknowledgements}

This research was funded by the Seventh Framework Programme of the European Commission (The COSPATIAL project - Grant Agreement no. 231266). I am very grateful to: the schools, teachers and pupils for their generous participation and feedback; COSPATIAL colleagues at the University of Nottingham for their technical expertise; Sara Garib-Penna for data collection, analysis and contributions to draft reports; and Carolyn Payne and Willeke Rietdijk for support with inter-rater coding. 


\section{References}

Abascal, J., \& Nicolle, C. (2005). Moving towards inclusive design guidelines for socially and ethically aware HCI. Interacting with Computers, 17(5), 484-505.

Abbott, C. (2007) e-Inclusion: Learning Difficulties and Digital Technologies. Bristol: Futurelab. www.futurelab.org.uk [last accessed $5^{\text {th }}$ August 2014].

American Psychiatric Association. (2013). Diagnostic and statistical manual of mental disorders (5th ed.). Washington, DC: Author.

Aronson, E. \& Patnoe, S. (2011). Cooperation in the classroom: the Jigsaw Method (3rd edition). Pinter \& Martin Ltd.

Baird, G., Simonoff, E., Pickles, A., Chandler, S., Loucas, T., Meldrum, D., \& Charman, T. (2006). Prevalence of disorders of the autism spectrum in a population cohort of children in South Thames: the Special Needs and Autism Project (SNAP). The Lancet, 368(9531), 210-215.

Baron-Cohen, S., Leslie, A.M. \& Frith, U. (1985). Does the autistic child have a 'theory of mind'? Cognition, 21(1), 37-46.

Bauminger, N. (2002). The facilitation of social-emotional understanding and social interaction in high functioning children with autism: Intervention outcomes. Journal of Autism and Developmental Disorders, 32(4), 283-298.

Bauminger, N. (2007a). Individual Social-Multi-Modal Intervention for HFASD. Journal of Autism and Developmental Disorders, 37(8), 1593-1604.

Bauminger, N. (2007b). Group Social-Multimodal Intervention for HFASD. Journal of Autism and Developmental Disorders, 37(8), 1605-1615.

Bauminger-Zviely, N., Eden, S., Zancanaro, M., Weiss, P. L., \& Gal, E. (2013). Increasing social engagement in children with high-functioning autism spectrum disorder using collaborative technologies in the school environment. Autism, 17(3), 317-339.

Beardon, L., Parsons, S. \& Neale, H. (2001) An inter-disciplinary approach to investigating the use of virtual reality environments for people with Asperger Syndrome. Educational and Child Psychology, 18(2), 53-62. 
Benton, L., Johnson, H., Ashwin, E., Brosnan, M., \& Grawemeyer, B. (2012, May). Developing IDEAS: Supporting children with autism within a participatory design team. In Proceedings of the SIGCHI conference on Human factors in computing systems (pp. 2599-2608). ACM.

Buescher, A. V., Cidav, Z., Knapp, M., \& Mandell, D. S. (2014). Costs of autism spectrum disorders in the United Kingdom and the United States. JAMA Pediatrics, 168, 721-728.

Boser, K.,Goodwin, M.S., \& Wayland, S. (Eds.) (2013). Technology Tools for Students with Autism: Innovations that Enhance Independence and Learning. Baltimore, MD: Brookes Publishing.

Bosseler, A., \& Massaro, D. W. (2003). Development and evaluation of a computer-animated tutor for vocabulary and language learning in children with autism. Journal of Autism and Developmental Disorders, 33(6), 653-672.

Brown, D. J., McHugh, D., Standen, P., Evett, L., Shopland, N., \& Battersby, S. (2011). Designing location-based learning experiences for people with intellectual disabilities and additional sensory impairments. Computers \& Education, 56(1), 11-20.

Brugha, T. S., McManus, S., Bankart, J., Scott, F., Purdon, S., Smith, J., ... \& Meltzer, H. (2011). Epidemiology of autism spectrum disorders in adults in the community in England. Archives of General Psychiatry, 68(5), 459-465.

Cheng, Y., \& Ye, J. (2010). Exploring the social competence of students with autism spectrum conditions in a collaborative virtual learning environment -The pilot study. Computers \& Education, 54(4), 1068-1077.

Cobb, S., Beardon, L., Eastgate, R., Glover, T., Kerr, S., Neale, H., Parsons, S., Benford, S., Hopkins, E., Mitchell, P., Reynard, G. and Wilson, J.R. (2002) Applied virtual environments to support learning of social interaction skills in users with Asperger's Syndrome. Digital Creativity, 13, $11-22$.

Cobb, S., Millen, L., Glover, T., Hawkins, T., Patel, H., Eastgate, R., Parsons, S., \& Garib-Penna, S. (2010) Collaborative VE: Experience Report and Prototypes. FP7 Deliverable 4.1.2. Available at http://cospatial.fbk.eu/deliverables [last accessed 23rd October 2015]. 
Cobb, S. Parsons, S., Millen, L., Eastgate, R. \& Glover, T. (2010). Design and development of collaborative technology for children with autism: COSPATIAL. Proceedings of INTED2010 Conference, 8-10 March 2010, Valencia, Spain, 4374-4383.

Dahlgren, S. \& Dahlgren-Sandberg, A. (2008). Referential communication in children with autism spectrum disorder. Autism, 12(4), 335-348.

Dalgarno, B., \& Lee, M. J. (2010). What are the learning affordances of 3-D virtual environments?. British Journal of Educational Technology, 41(1), 10-32.

Davis, M., Dautenhahn, K., Powell, S., \& Nehaniv, C. (2010). Guidelines for researchers and practitioners designing software and software trials for children with autism. Journal of Assistive Technologies, 4(1), 38-48.

Davis, P. \& Florian, L. et al., (2004) Teaching Strategies and Approaches for Pupils with Special Educational Needs: A Scoping Study. Research Report No.516 DfES Publications: Nottingham. http://dera.ioe.ac.uk/6059/1/RR516.pdf [last accessed 22nd October 2015].

Dickey, M. D. (2005). Brave new (interactive) worlds: A review of the design affordances and constraints of two 3D virtual worlds as interactive learning environments. Interactive Learning Environments, 13(1-2), 121-137.

Dillon, G., \& Underwood, J. (2012). Computer mediated imaginative storytelling in children with autism. International Journal of Human-Computer Studies, 70(2), 169-178.

Dunn, L. M., Dunn, D. M., Styles, B. \& NFER - Sewell, J. (2009). The British Picture Vocabulary Scale 3rd Edition (BPVS III). GL Assessment, London, UK.

Emslie, H., Wilson, C. F., Burden, V., Nimmo-Smith, I., Wilson, B. A. (2003). Behavioural Assessment of the Dysexecutive Syndrome for Children (BADS-C), Thames Valley Test Company, Bury St. Edmunds.

Frauenberger, C., Good, J., Alcorn, A., \& Pain, H. (2013). Conversing through and about technologies: Design critique as an opportunity to engage children with autism and broaden research (er) perspectives. International Journal of Child-Computer Interaction, 1(2), 38-49. 
Goodwin, M. S. (2008). Enhancing and accelerating the pace of autism research and treatment. Focus on Autism and Other Developmental Disabilities, 23(2), 125-128.

Grynszpan, O., Weiss, P. L. T., Perez-Diaz, F., \& Gal, E. (2014). Innovative technology-based interventions for autism spectrum disorders: A meta-analysis. Autism, 18(4), 346-361.

Guldberg, K. (2010). Educating children on the autism spectrum: preconditions for inclusion and notions of 'best autism practice' in the early years. British Journal of Special Education, 37(4), $168-174$

Guldberg, K., Parsons, S., MacLeod, A., Jones, G., Prunty, A., \& Balfe, T. (2011). Implications for practice from 'International review of the evidence on best practice in educational provision for children on the autism spectrum'. European Journal of Special Needs Education, 26(1), 6570.

Hamilton, A. F. de C., Brindley, R., \& Frith, U. (2009). Visual perspective impairment in children with autistic spectrum disorder. Cognition, 113(1), 37-44

Harrison, S., Sengers, P., \& Tatar, D. (2011). Making epistemological trouble: Third-paradigm HCI as successor science. Interacting with Computers, 23(5), 385-392.

Higgins, S., Xiao, Z., \& Katsipataki, M. (2012).The Impact of Digital Technology on Learning: A Summary for the Education Endowment Foundation (Full Report). Available from http://educationendowmentfoundation.org.uk/toolkit/publications/ [last accessed $6^{\text {th }}$ February 2015].

Holt, S., \& Yuill, N. (2014). Facilitating other-awareness in low-functioning children with autism and typically-developing preschoolers using dual-control technology. Journal of Autism and Developmental Disorders, 44(1), 236-248.

Jordan, R. (2005). Autistic spectrum disorders. Chapter in B. Norwich and A. Lewis (Eds) (2005) Special teaching for special children?: pedagogies for inclusion. Maidenhead, England: McGrawHill International (pp.110-122).

Kasari, C. \& Smith, T. (2013) Interventions in schools for children with autism spectrum disorder: Methods and recommendations, Autism, 17(3), 254-267. 
Ke, F. \& Im, T. (2013) Virtual-Reality-Based Social Interaction Training for Children with HighFunctioning Autism, The Journal of Educational Research, 106(6), 441-461.

Keintz, J., Goodwin, M.S., Hayes, G., \& Abowd, G. (2014). Interactive Technologies for Autism. Synthesis Lectures on Assistive, Rehabilitative, and Health-Preserving Technologies. San Rafael, CA: Morgan \& Claypool.

Knight, V., McKissick, B. R., \& Saunders, A. (2013). A review of technology-based interventions to teach academic skills to students with autism spectrum disorder. Journal of Autism and Developmental Disorders, 43(11), 2628-2648.

Loncola, J, A and Craig-Unkefer, L (2005). Teaching Social Communication Skills to Young Urban Children with Autism. Education and Training in Developmental Disabilities 40(3), 243-263.

Lord, C., Rutter, M., Goode, S., Heemsbergen, J., Jordan, H., Mawhood, L., \& Schopler, E. (1989). Austism diagnostic observation schedule: A standardized observation of communicative and social behavior. Journal of Autism and Developmental Disorders, 19(2), 185-212.

Madsen, M., El Kaliouby, R., Eckhardt, M., Hoque, M. E., Goodwin, M. S., \& Picard, R. (2009, April). Lessons from participatory design with adolescents on the autism spectrum. In $\mathrm{CHI}^{\prime} 09$ Extended Abstracts on Human Factors in Computing Systems (pp. 3835-3840). ACM.

Mavrou, K. Computer based collaborative learning of disabled and non-disabled pupils in mainstream classrooms in Cyprus: cases of peer interaction analysis in pairs. $\mathrm{PhD}$ Thesis, University of Birmingham, UK.

Mavrou, K., Lewis, A. \& Douglas, G. (2010) Researching computer-based collaborative learning in inclusive classrooms in Cyprus: the role of the computer in pupils' interaction. British Journal of Educational Technology, 41(3), 486-501

Mavrou, K., Lewis, A. \& Douglas, G. (2007) The use of Transana as a video analysis tool in researching computer-based collaborative learning in inclusive classrooms in Cyprus. International Journal of Research and Method in Education, 30(2),163-178. 
McConnell, S. R. (2002) Interventions to Facilitate Social Interaction for Young Children with Autism: Review of Available Research and Recommendations for Educational Intervention and Future Research. Journal of Autism and Developmental Disorders, 32(5), 351-372.

Menzies, R. (2011) Promoting sharing behaviours in children through the use of a customised novel computer system, ACM SIGACCESS Accessibility and Computing, 99, 30-36.

Millen, L. (2014). Methods for supporting participatory design with children with autism spectrum conditions. Unpublished PhD Thesis, University of Nottingham, Nottingham, UK.

Millen, L., Cobb, S., \& Patel, H. (2011). Participatory design approach with children with autism. International Journal on Disability and Human Development, 10(4), 289-294.

Mitchell, P., Parsons, S. \& Leonard, A. (2007). Using virtual environments for teaching social understanding to adolescents with autistic spectrum disorders. Journal of Autism and Developmental Disorders, 37(3), 589-600.

Nesset, V., \& Large, A. (2004). Children in the information technology design process: A review of theories and their applications. Library \& Information Science Research, 26(2), 140-161.

Nilsen, E.S. \& Fecica, A.M. (2011) A model of communicative perspective-taking for typical and atypical populations of children. Developmental Review, 31(1), 55-78.

Nind, M., \& Wearmouth, J. (2006). Including children with special educational needs in mainstream classrooms: implications for pedagogy from a systematic review. Journal of Research in Special Educational Needs, 6(3), 116-124.

Ogletree, B.T., Oren, T. \& Fischer, M.A. (2007) Examining effective intervention practices for communication impairment in Autism Spectrum Disorder. Exceptionality: A Special Education Journal, 15(4), 233-247.

Owen-DeSchryver, J.S., Carr, E.G., Cale, S.I. and Blakeley-Smith, A. (2008). Promoting social interactions between students with autism spectrum disorders and their peers in inclusive school settings. Focus on Autism and Other Developmental Disabilities, 23(1), 15-28.

Parsons, S., Beardon, L., Neale, H. R., Reynard, G., Eastgate, R., Wilson, J. R., Cobb, S. V., Benford, S., Mitchell, P., \& Hopkins, E. (2000). Development of social skills amongst adults with 
Asperger's Syndrome using virtual environments: The AS Interactive project. $3^{\text {rd }}$ International Conference on Disability, Virtual Reality and Associated Technologies, Sardinia, 23-25th September, 2000, pp 163-170.

Parsons, S., Charman, T., Faulkner, R., Ragan, J., Wallace, S. \& Wittemeyer, K. (2013) Bridging the research and practice gap in autism: the importance of creating research partnerships with schools. Autism, 17(3), 268-280.

Parsons, S. \& Cobb, S. (2011) State-of-the art of Virtual Reality Technologies for children on the autism spectrum. European Journal of Special Needs Education, 26(3), 355-36

Parsons, S. \& Cobb, S. (2014) Reflections on the role of the 'users': challenges in a multidisciplinary context of learner-centred design for children on the autism spectrum. International Journal of Research and Method in Education, 37(4), 421-441.

Parsons, S., Garib-Penna, S., Millen, L., Cobb, S., Hawkins, T., Weiss, P.L., ... \& Zancanaro, M. (2011a) Deliverable 5.1.: Report on the design of the evaluation studies. Available at http://cospatial.fbk.eu/deliverables [last accessed 29th July 2013].

Parsons, S., Guldberg, K., MacLeod, A., Jones, G., Prunty, A., \& Balfe, T. (2011b). International review of the evidence on best practice in educational provision for children on the autism spectrum. European Journal of Special Needs Education, 26(1), 47-63.

Parsons, S., Leonard, A. \& Mitchell, P. (2006). Virtual environments for social skills training: comments from two adolescents with autistic spectrum disorder. Computers \& Education, 47(2), 186-206.

Parsons, S., Millen, L., Garib-Penna, S. \& Cobb, S. (2011) Participatory design in the development of innovative technologies for children and young people on the autism spectrum: the COSPATIAL project. Journal of Assistive Technologies, 5(1), 29-34.

Parsons, S., Mitchell, P., \& Leonard, A. (2005). Do adolescents with autistic spectrum disorders adhere to social conventions in virtual environments? Autism, 9(1), 95-117.

Pellicano, E., Dinsmore, A., \& Charman, T. (2014) 'What should autism research focus upon? Community views and priorities from the United Kingdom. Autism, 18(7), 756-770. 
Pellicano, E., \& Stears, M. (2011). Bridging autism, science and society: moving toward an ethically informed approach to autism research. Autism Research, 4(4), 271-282.

Perner, J. \& Wimmer, H. (1985). "John thinks that Mary thinks that..." Attribution of second-order beliefs by 5-10 year old children. Journal of Experimental Child Psychology, 39, 437-471.

Ploog, B. O., Scharf, A., Nelson, D., \& Brooks, P. J. (2013). Use of computer-assisted technologies (CAT) to enhance social, communicative, and language development in children with autism spectrum disorders. Journal of Autism and Developmental Disorders, 43(2), 301-322.

Prendeville, J., Prelock, P. A., \& Unwin, G. (2006). Peer play interventions to support the social competence of children with autism spectrum disorders. Seminars in Speech and Language, 27(1), 32-46.

Prizant, B. M., \& Rubin, E. (1999). Contemporary Issues in Interventions for Autism Spectrum Disorders: A Commentary. Journal of the Association for Persons with Severe Handicaps, 24(3), 199-208.

Porayska-Pomsta, K., Frauenberger, C., Pain, H., Rajendran, G., Smith, T., Menzies, R., ... \& Lemon, O. (2012). Developing technology for autism: an interdisciplinary approach. Personal and Ubiquitous Computing, 16(2), 117-127.

Ravet, J. (2011). Inclusive/exclusive? Contradictory perspectives on autism and inclusion: the case for an integrative position. International Journal of Inclusive Education, 15(6), 667-682.

Reed, F. D. D., Hyman, S. R., \& Hirst, J. M. (2011). Applications of technology to teach social skills to children with autism. Research in Autism Spectrum Disorders, 5(3), 1003-1010.

Rutter, M., Bailey, A., \& Lord, C. (2003). SCQ: The Social Communication Questionnaire-Manual. Los Angeles, CA: Western Psychological Services.

Schmidt, M., Laffey, J. M., Schmidt, C. T., Wang, X., \& Stichter, J. (2012). Developing methods for understanding social behavior in a 3D virtual learning environment. Computers in Human Behavior, 28(2), 405-413. 
Silver, M., \& Oakes, P. (2001). Evaluation of a new computer intervention to teach people with autism or Asperger syndrome to recognize and predict emotions in others. Autism, 5(3), 299316.

Whitaker, P. (2007) Provision for youngsters with autistic spectrum disorders in mainstream schools: what parents say - and what parents want. British Journal of Special Education, 34(3), 170-178.

Wass, S.V. \& Porayska-Pomsta, K. (2014) The uses of cognitive training technologies in the treatment of autism spectrum disorders Autism, 18(8), 851-871.

Wechsler, D. (1999). Wechsler Abbreviated Scale of Intelligence (WASI). Psychological Corporation, San Antonio.

Weiss, P.L.(T), Gal, E., Zancanaro, M., Pianesi, F., Stock, O., Cobb, S., ... \& Parsons, S. (2012) A CBTbased Framework to Design Collaborative Technologies for Learning Social Competencies. COSPATIAL project deliverable report D2.2.3 Available from: http://cospatial.fbk.eu/deliverables. [Last accessed 6th February 2015].

Williams White, S., Keonig, K. \& Scahill, L. (2007) Social Skills Development in Children with Autism Spectrum Disorders: A Review of the Intervention Research. Journal of Autism and Developmental Disorders, 37(10), 1858-1868.

Wittemeyer, K., Charman, T., Cusack, J., Guldberg, K., Hastings, R., Howlin, P., ... \& Slonims, V. (2011) Educational provision and outcomes for people on the autism spectrum: Full technical report. Autism Education Trust. http://www.autismeducationtrust.org.uk/outcomes/ [last accessed 23 $3^{\text {rd }}$ October 2015].

Woods, D, \& Fassnacht, C. (2010). Transana v2.42. http://www.transana.org. Madison, WI: The Board of Regents of the University of Wisconsin System.

Yelland, N., \& Masters, J. (2007). Rethinking scaffolding in the information age. Computers \& Education, 48(3), 362-382.

Zancanaro, M., Giusti, L., Bauminger-Zviely, N., Eden, S., Gal, E., \& Weiss, P. L. (2014). NoProblem! A Collaborative Interface for Teaching Conversation Skills to Children with High Functioning 
Autism Spectrum Disorder. Chapter in A. Nijholt (Ed.) (2014) Playful User Interfaces (pp. 209224). Springer Singapore. 
Tables

Table 1: Mean and standard deviations for age, language, IQ, and executive function; and number of children passing ToM tasks

\begin{tabular}{|c|c|c|c|c|c|c|c|c|c|}
\hline & $N$ & & $\begin{array}{l}\text { Chronological } \\
\text { Age }\end{array}$ & $\begin{array}{l}\text { Verbal } \\
\text { Mental } \\
\text { Age } \\
\text { (BPVS) }\end{array}$ & $\begin{array}{l}\text { BADS-C } \\
\text { Overall } \\
\text { Age- } \\
\text { Scaled } \\
\text { Score }\end{array}$ & $\begin{array}{l}\text { DEX-C } \\
\text { Qu'aire } \\
\text { (Out of } \\
\text { 80) }\end{array}$ & $\begin{array}{l}\text { Full } \\
\text { Scale IQ } \\
\text { (WASI) }\end{array}$ & $\begin{array}{l}\text { First } \\
\text { Order } \\
\text { ToM }\end{array}$ & $\begin{array}{l}\text { Second } \\
\text { Order } \\
\text { ToM }\end{array}$ \\
\hline \multirow[t]{2}{*}{ ASD } & 6 & Mean & 11.07 & 9.03 & 43.17 & 42.33 & 96 & 5 & 2 \\
\hline & & s.d. & 1.05 & 3.08 & 14.16 & 15.51 & 27.6 & & \\
\hline \multirow[t]{2}{*}{ TD } & 8 & Mean & 8.04 & 8.00 & 54.88 & 5.14 & 115 & 8 & 2 \\
\hline & & s.d. & 0.08 & 0.08 & 7.92 & 7.58 & 9.7 & & \\
\hline
\end{tabular}

Table 2: Individual scores for each child on cognitive, language and ToM tasks [1=pass, $0=$ fail] and number of turns taken by each child and facilitators to complete the three levels of Block Challenge $\left[{ }^{*}=\right.$ missing data $]$

\begin{tabular}{|c|c|c|c|c|c|c|c|c|}
\hline Pair & & VMA & BADS & DEX & ToM1 & ToM2 & $\begin{array}{l}\text { Total no. of } \\
\text { moves by } \\
\text { child }\end{array}$ & $\begin{array}{l}\text { Total no of } \\
\text { moves by } \\
\text { facilitator }\end{array}$ \\
\hline ASD1 & $\begin{array}{l}\text { Child A } \\
\text { Child B }\end{array}$ & $\begin{array}{l}6.01 \\
8.07\end{array}$ & $\begin{array}{l}30 \\
56\end{array}$ & $\begin{array}{l}44 \\
65\end{array}$ & $\begin{array}{l}1 \\
1\end{array}$ & $\begin{array}{l}0 \\
0\end{array}$ & $\begin{array}{l}54 \\
45\end{array}$ & $\begin{array}{l}105 \\
88\end{array}$ \\
\hline ASD2 & $\begin{array}{l}\text { Child C } \\
\text { Child D }\end{array}$ & $\begin{array}{l}11.0 \\
15.09\end{array}$ & $\begin{array}{l}55 \\
57\end{array}$ & $\begin{array}{l}44 \\
23\end{array}$ & $\begin{array}{l}1 \\
1\end{array}$ & $\begin{array}{l}1 \\
1\end{array}$ & $\begin{array}{l}62 \\
60\end{array}$ & $\begin{array}{l}29 \\
11\end{array}$ \\
\hline ASD3 & $\begin{array}{l}\text { Child E } \\
\text { Child F }\end{array}$ & $\begin{array}{l}8.03 \\
5.11\end{array}$ & $\begin{array}{l}33 \\
28\end{array}$ & $\begin{array}{l}27 \\
51\end{array}$ & $\begin{array}{l}1 \\
0\end{array}$ & $\begin{array}{l}0 \\
0\end{array}$ & $\begin{array}{l}113 \\
117\end{array}$ & $\begin{array}{l}236 \\
177\end{array}$ \\
\hline TD1 & $\begin{array}{l}\text { Child G } \\
\text { Child H }\end{array}$ & $\begin{array}{l}7.1 \\
7.02\end{array}$ & $\begin{array}{l}58 \\
56\end{array}$ & $\begin{array}{l}0 \\
7\end{array}$ & $\begin{array}{l}1 \\
1\end{array}$ & $\begin{array}{l}0 \\
1\end{array}$ & $\begin{array}{l}33 \\
32\end{array}$ & $\begin{array}{l}46 \\
36\end{array}$ \\
\hline TD2 & $\begin{array}{l}\text { Child I } \\
\text { Child J }\end{array}$ & $\begin{array}{l}9.07 \\
8.02\end{array}$ & $\begin{array}{l}60 \\
40\end{array}$ & $\begin{array}{l}20 \\
*\end{array}$ & $\begin{array}{l}1 \\
1\end{array}$ & $\begin{array}{l}0 \\
0\end{array}$ & $\begin{array}{l}32 \\
43\end{array}$ & $\begin{array}{l}26 \\
30\end{array}$ \\
\hline TD3 & $\begin{array}{l}\text { Child K } \\
\text { Child L }\end{array}$ & $\begin{array}{l}7.08 \\
8.04\end{array}$ & $\begin{array}{l}56 \\
56\end{array}$ & $\begin{array}{l}0 \\
0\end{array}$ & $\begin{array}{l}1 \\
1\end{array}$ & $\begin{array}{l}1 \\
0\end{array}$ & $\begin{array}{l}30 \\
43\end{array}$ & $\begin{array}{l}33 \\
33\end{array}$ \\
\hline TD4 & $\begin{array}{l}\text { Child M } \\
\text { Child N }\end{array}$ & $\begin{array}{l}7.11 \\
7.1\end{array}$ & $\begin{array}{l}52 \\
50\end{array}$ & $\begin{array}{l}0 \\
9\end{array}$ & $\begin{array}{l}1 \\
1\end{array}$ & $\begin{array}{l}0 \\
0\end{array}$ & $\begin{array}{l}70 \\
69\end{array}$ & $\begin{array}{l}96 \\
82\end{array}$ \\
\hline
\end{tabular}


Table 3: Inductive coding of children's behaviours mapped to behavioural categories from Holt and Yuill (2014)

\begin{tabular}{|c|c|c|}
\hline $\begin{array}{l}\text { Initial inductive codes of } \\
\text { verbal and non-verbal } \\
\text { [NV] behaviours of the } \\
\text { children using Block } \\
\text { Challenge }\end{array}$ & Example comment or action & $\begin{array}{l}\text { Behavioural } \\
\text { categories from } \\
\text { Holt \& Yuill (2014) }\end{array}$ \\
\hline Agree & I agree with you... and I agree with myself! & \multirow{13}{*}{$\begin{array}{l}\text { Active other } \\
\text { awareness (ACO) - } \\
\text { intentional } \\
\text { relationship to } \\
\text { partner's } \\
\text { comment or } \\
\text { action }\end{array}$} \\
\hline Attention & $\begin{array}{l}\text { Getting partner's attention, e.g. by saying their } \\
\text { name before speaking }\end{array}$ & \\
\hline Co-ordinate play & $\begin{array}{l}\text { Verbally co-ordinate actions in CVE: } \\
\text { e.g., } 1,2,3 \text {...rotate! }\end{array}$ & \\
\hline $\begin{array}{l}\text { Describe - } \\
\text { Action/Intention/Decision- } \\
\text { making }\end{array}$ & $\begin{array}{l}\text { 'So I'm clicking on the red and yellow one'; so } \\
\text { I've chosen the red and yellow one'; 'I'm going } \\
\text { to click rotate' }\end{array}$ & \\
\hline Disagree & $\begin{array}{l}\text { I don't think that's the right one'; 'no we need } \\
\text { this one'; 'No!' }\end{array}$ & \\
\hline Inform & $\begin{array}{l}\text { 'So I need the yellow one' } \\
\text { 'My bottom target is red' }\end{array}$ & \\
\hline Instruct & $\begin{array}{l}\text { 'Click on the pink and yellow' } \\
\text { 'Press stop then' }\end{array}$ & \\
\hline Invite & 'Come on then, let's rotate!' & \\
\hline Justify & $\begin{array}{l}\text { 'I need to switch blocks because I'm not happy } \\
\text { with the one we picked' }\end{array}$ & \\
\hline Offer Help & $\begin{array}{l}\text { 'If we turn the block then you will see the } \\
\text { yellow side and I will see the blue side so that's } \\
\text { what we need to do' }\end{array}$ & \\
\hline Protest & $\begin{array}{l}\text { 'Why do you want to switch the block? I don't } \\
\text { want to!' }\end{array}$ & \\
\hline Question - Task Relevant & 'What colour do you need?' & \\
\hline Suggest & 'Should we rotate the block?' & \\
\hline Accept [NV] & $\begin{array}{l}\text { Non-verbal version of agree e.g. clicking on the } \\
\text { rotate button in response to: "we need to } \\
\text { rotate the block" }\end{array}$ & \multirow{5}{*}{$\begin{array}{l}\text { Attentional other } \\
\text { awareness (ATO) - } \\
\text { related to but not } \\
\text { contingent on the } \\
\text { other's action }\end{array}$} \\
\hline Acknowledge & $\mathrm{OK}$ & \\
\hline Confirm & Ok, so we need a yellow and a blue one & \\
\hline Quiet/softly spoken & $\begin{array}{l}\text { Speaks/answers in a quiet voice that may not } \\
\text { heard / understood }\end{array}$ & \\
\hline Sharing Reasoning & $\begin{array}{l}\text { Reasoning / problem-solving out loud or } \\
\text { explaining an action or a comment / instruction } \\
\text { / suggestion. }\end{array}$ & \\
\hline $\begin{array}{l}\text { Acting with no description } \\
\text { [NV] }\end{array}$ & $\begin{array}{l}\text { Acting within the CVE without any } \\
\text { communication with partner }\end{array}$ & \\
\hline Answer - Task Relevant & $\begin{array}{l}\text { Simple factual answer to a task relevant } \\
\text { question. E.g., I need a blue }\end{array}$ & \\
\hline Confused & 'Umm, I'm not sure...' & \\
\hline
\end{tabular}




\begin{tabular}{|c|c|c|}
\hline Literal & $\begin{array}{l}\text { Uses information literally rather than within } \\
\text { context }\end{array}$ & \multirow{8}{*}{$\begin{array}{l}\text { Approach to task } \\
\text { (APT) - task- } \\
\text { related } \\
\text { behaviours not } \\
\text { directed at the } \\
\text { other child }\end{array}$} \\
\hline Reading & $\begin{array}{l}\text { Reading out the instructions provided by } \\
\text { Professor Blocks within the CVE }\end{array}$ & \\
\hline Shows enjoyment & $\begin{array}{l}\text { Whilst playing task. E.g., laughing or making } \\
\text { positive comment about task }\end{array}$ & \\
\hline Talks about feelings & $\begin{array}{l}\text { How they feel in the given situation: e.g. 'I'm } \\
\text { really enjoying this', 'this is stressful' }\end{array}$ & \\
\hline Uses Facilitator feedback & $\begin{array}{l}\text { Acts on facilitator feedback or takes it into } \\
\text { account when performing task e.g. 'She needs } \\
\text { that one (points to block with mouse) and that } \\
\text { one' [following a question from facilitator: why } \\
\text { don't you find out what xxxx needs?] }\end{array}$ & \\
\hline $\begin{array}{l}\text { Describe - Physical } \\
\text { attributes of room }\end{array}$ & $\begin{array}{l}\text { No purpose to description other than to tell } \\
\text { partner what s/he can see in the CVE room } \\
\text { (exercise at the beginning of game) }\end{array}$ & \\
\hline Greeting & Hello! & \\
\hline Positive Feedback & $\begin{array}{l}\text { 'Well done!' } \\
\text { 'We did it!' }\end{array}$ & \\
\hline Distracted [NV] & $\begin{array}{l}\text { Is distracted from the game and as a } \\
\text { consequence does not seem to pay full } \\
\text { attention to the communication with partner } \\
\text { (does not respond when spoken to or is slow to } \\
\text { respond). }\end{array}$ & \multirow{6}{*}{$\begin{array}{l}\text { Withdrawal from } \\
\text { task (WFT) - non- } \\
\text { task related } \\
\text { behaviours }\end{array}$} \\
\hline $\begin{array}{l}\text { Does not offer info in } \\
\text { return/does not ask for } \\
\text { info in return [NV] }\end{array}$ & $\begin{array}{l}\text { Child A has offered or asked for relevant } \\
\text { information ('I need a yellow' or 'What colour } \\
\text { do you need?') and Child B does not offer the } \\
\text { corresponding relevant information; stays } \\
\text { silent. }\end{array}$ & \\
\hline Ignore & $\begin{array}{l}\text { Ignores specific communication made by } \\
\text { partner by responding with a non-related } \\
\text { verbal response. }\end{array}$ & \\
\hline $\begin{array}{l}\text { Ignore Facilitator feedback } \\
\text { [NV] }\end{array}$ & $\begin{array}{l}\text { Ignores feedback from the facilitator that } \\
\text { would help resolve an issue that has arisen } \\
\text { within the game (such as collaboration / } \\
\text { communication / perspective taking). }\end{array}$ & \\
\hline Off-task behaviour & $\begin{array}{l}\text { Chasing each other's avatars within the CVE or } \\
\text { commenting on an aspect of the game that is } \\
\text { not related to the completion of the task. } \\
\text { e.g. (Looks at the blocks) 'Oh my God' (moves } \\
\text { avatar side to side) 'I'm a block!' }\end{array}$ & \\
\hline Uncooperative [NV] & $\begin{array}{l}\text { Refuses to play along or makes it difficult for } \\
\text { partner to play game e.g. looking in different } \\
\text { parts of the room rather than at the block. }\end{array}$ & \\
\hline
\end{tabular}


Table 4: Codes of verbal interactions between facilitators and children

\begin{tabular}{|c|c|}
\hline $\begin{array}{l}\text { Facilitator to child } \\
\text { interactions }\end{array}$ & Example \\
\hline $\begin{array}{l}\text { Brings child's attention } \\
\text { back to task }\end{array}$ & 'Sam, look at what Professor Blocks is asking you to do' \\
\hline Clarifying Directive & $\begin{array}{l}\text { Giving an instruction and explaining it E.g., 'So, you need to click on } \\
\text { the brown and yellow block because you need brown and Johnny } \\
\text { needs yellow'; 'If you say his name, he will know to pay attention to } \\
\text { you' }\end{array}$ \\
\hline Communication Focus & $\begin{array}{l}\text { Scaffolding the communication. E.g., 'Can you ask Johnny what he } \\
\text { needs?' 'Did you hear what Sam just said?' }\end{array}$ \\
\hline Concept Focus & $\begin{array}{l}\text { Checking / explaining the underlying concepts i.e. that the } \\
\text { conversational partner has a different perspective on the task and } \\
\text { different needs for successful completion e.g. 'So, why is Johnny } \\
\text { asking for a yellow block?' Also explaining the concept of } \\
\text { collaboration (not just perspective-taking) e.g., 'So you need ask Sam } \\
\text { what colour he needs and tell him what colour you need so that you } \\
\text { can choose the right block for both of you' }\end{array}$ \\
\hline $\begin{array}{l}\text { Modelling } \\
\text { Communication }\end{array}$ & $\begin{array}{l}\text { Telling the child exactly what to say to partner e.g., 'why don't you say } \\
\text { 'Sam, what's the colour of your block on the bottom?' }\end{array}$ \\
\hline Praise & 'Well done! You told Sam which block you needed' \\
\hline $\begin{array}{l}\text { Procedural Focus } \\
\text { (Including helping to } \\
\text { read/reading) }\end{array}$ & $\begin{array}{l}\text { Reading task instructions from Prof. Blocks on the screen or providing } \\
\text { information about interacting with the game: 'So what does Professor } \\
\text { Blocks tell us to do...[reading instruction from the screen]' } \\
\text { 'Press A to move on...' }\end{array}$ \\
\hline Task Focus & $\begin{array}{l}\text { 'What colour do you need?' } \\
\text { 'So you need blue, what do you need to do next?' }\end{array}$ \\
\hline
\end{tabular}

Table 5: Frequencies and pair, and group, mean frequencies for collaboration coding

\begin{tabular}{|c|c|c|c|c|c|c|c|c|c|}
\hline \multirow[t]{2}{*}{ Frequencies } & \multicolumn{4}{|c|}{$\begin{array}{l}\text { Typically developing (TD) } \\
\text { pairs }\end{array}$} & \multirow{2}{*}{$\begin{array}{l}\text { TD } \\
\text { group } \\
\overline{\boldsymbol{x}}\end{array}$} & \multicolumn{3}{|c|}{ ASD pairs } & \multirow{2}{*}{$\begin{array}{l}\text { ASD } \\
\text { group } \\
\overline{\boldsymbol{x}}\end{array}$} \\
\hline & 1 & 2 & 3 & 4 & & 1 & 2 & 3 & \\
\hline $\begin{array}{l}\text { Active other } \\
\text { awareness } \\
\text { (AC0) }\end{array}$ & 68 & 83 & 89 & 120 & 90 & 95 & 218 & 123 & 145.3 \\
\hline $\begin{array}{l}\text { Approach to } \\
\text { task (APT) }\end{array}$ & 106 & 79 & 52 & 151 & 97 & 173 & 205 & 63 & 147 \\
\hline $\begin{array}{l}\text { Attentional } \\
\text { other } \\
\text { awareness } \\
\text { (AT0) }\end{array}$ & 56 & 25 & 24 & 60 & 41.2 & 74 & 175 & 25 & 91.3 \\
\hline $\begin{array}{l}\text { Withdrawal } \\
\text { from task } \\
\text { (WFT) }\end{array}$ & 5 & 5 & 4 & 10 & 6 & 60 & 39 & 26 & 41.6 \\
\hline Pair $\bar{x}$ & 58.7 & 48 & 42.2 & 85.2 & 58.6 & 100.5 & 159.2 & 94.8 & 106.3 \\
\hline
\end{tabular}




\section{Figures}
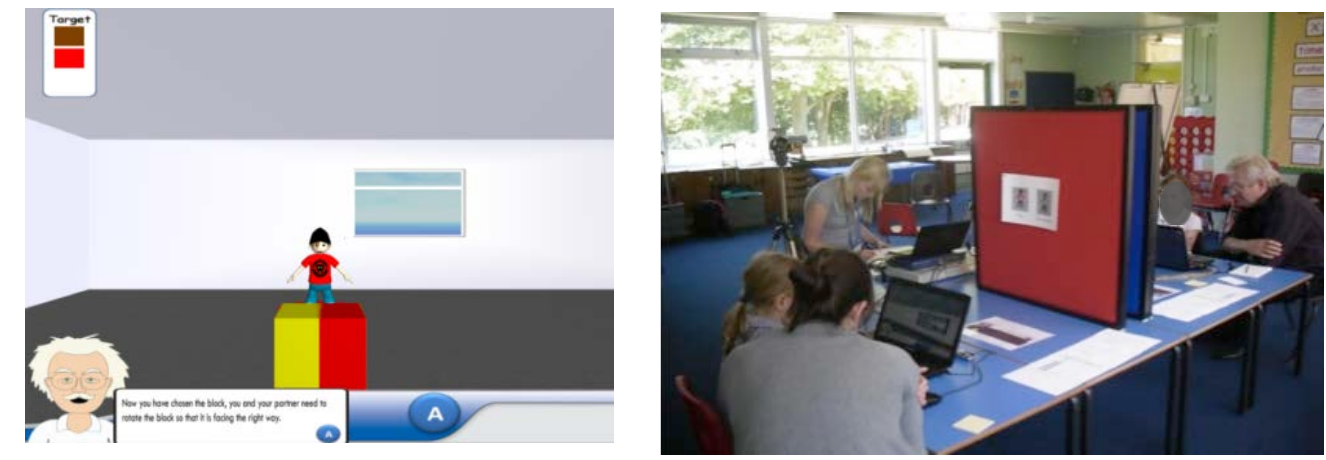

Figure 1: Screen shot from Block Challenge (left) and equipment set-up (right)

\begin{tabular}{|l|l|l|l|}
\hline \multicolumn{1}{|c|}{ Clip Start } & \multicolumn{1}{c|}{ Clip End } & \multicolumn{1}{c|}{ Collection ID } & \multicolumn{1}{c|}{ Clip ID } \\
\hline 0:00:00.0 & $0: 00: 02.9$ & Greeting & ASD3 \\
\hline $0: 00: 02.9$ & $0: 00: 04.3$ & Greeting & ASD4 \\
\hline $0: 00: 04.3$ & $0: 00: 04.9$ & Greeting & ASD3 - Laugh \\
\hline $0: 00: 07.3$ & $0: 00: 15.7$ & Describe - Physical attributes of room & ASD3 \\
\hline $0: 00: 16.4$ & $0: 00: 18.1$ & Communication Focus - Directive & F1 to ASD4 \\
\hline $0: 00: 18.5$ & $0: 00: 20.4$ & Describe - Physical attributes of room & ASD3;1 \\
\hline $0: 00: 21.3$ & $0: 00: 25.5$ & Query to Facilitator & ASD4 to F1 \\
\hline $0: 00: 26.2$ & $0: 00: 28.8$ & Communication Focus - Questioning & F1 to ASD4;1 \\
\hline $0: 00: 28.9$ & $0: 00: 30.5$ & Describe - Physical attributes of room & ASD4 \\
\hline
\end{tabular}

Figure 2: Excerpt from time-flow log from Transana showing the line-by-line coding (Collection ID column) and the "moves" of children and facilitators (Clip ID column) 


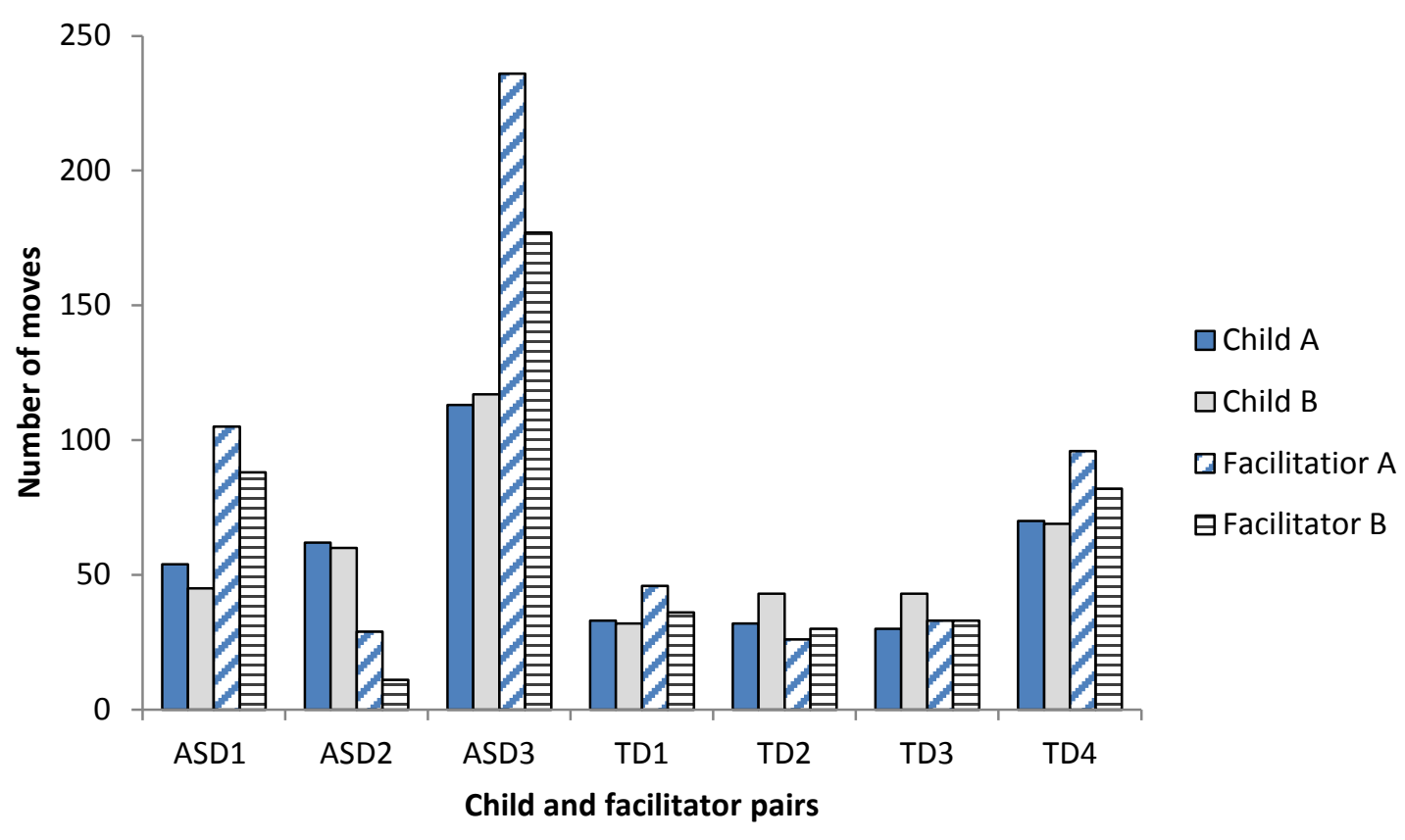

Figure 3: Total number of moves by children and facilitators within each pair

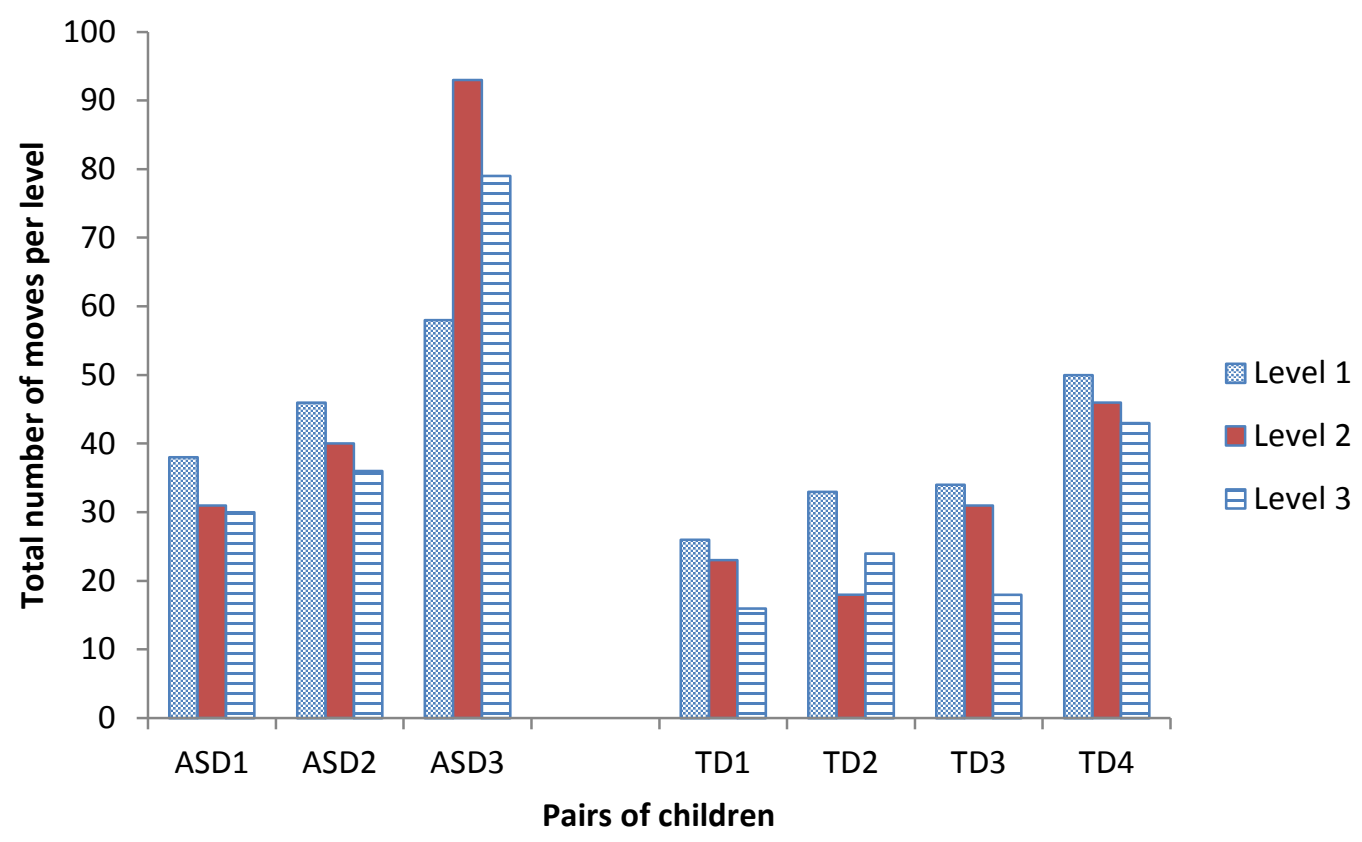

Figure 4: Number of moves taken within each pair across the three levels of the game 


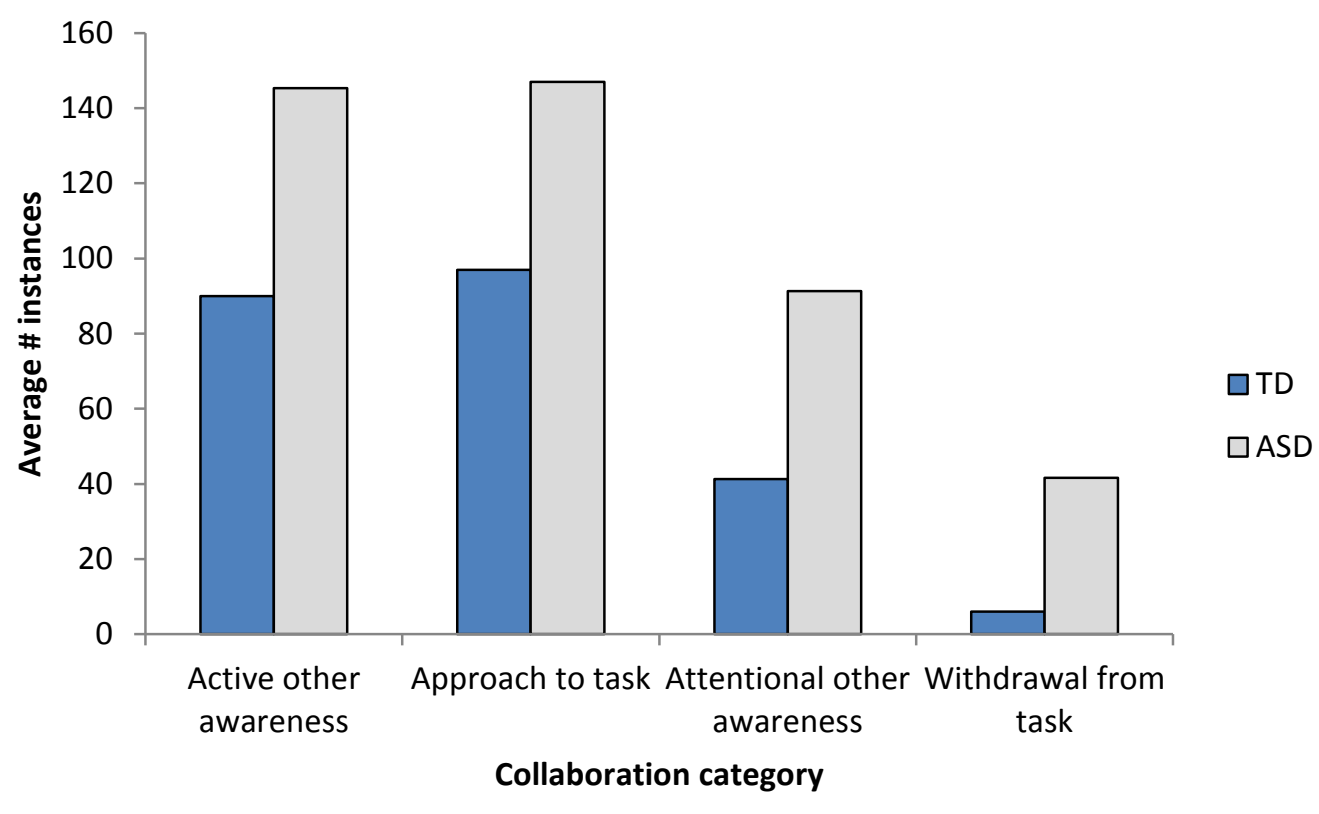

Figure 5: Average number of behavioural codes for the ASD and TD groups (based on Holt \& Yuill's, 2014, categories) 


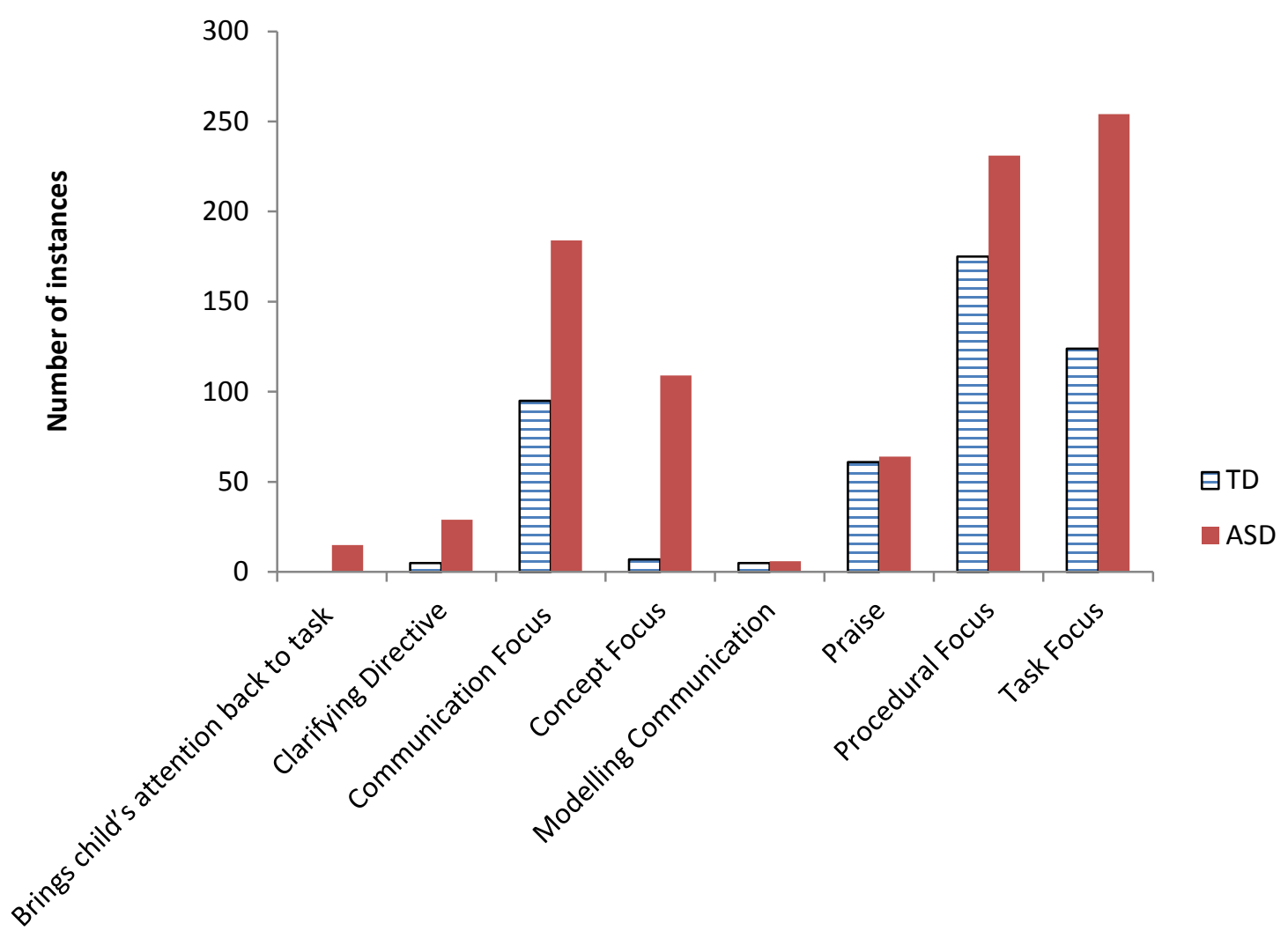

Facilitator input

Figure 6: Nature and frequency of facilitator input for ASD and TD pairs 